\title{
DEVELOPMENTAL DEFECTS IN THE LUNGS
}

\author{
BY \\ P. JONES \\ From the Brompton Hospital and London Chest Hospital
}

(RECEIVED FOR PUBLICATION APRIL 6, 1955)

An increasing number of congenital abnormalities of the lung is becoming recognized during life. Nineteen such cases of particular interest are described. They have been selected from a group of 37 patients with congenital lung defects, of which 35 have been operated on by one surgeon since 1939.

In five cases the intrathoracic abnormalities are threefold, in nine a double abnormality is present, while in two cases congenital abnormalities elsewhere in the body coexist with the pulmonary malformation.

Cases of purely vascular abnormality without pulmonary defect, for example, arteriovenous fistula, aneurysm, or pulmonary artery atresia, have not been included.

Brief reference to the embryology is necessary.

The tracheobronchial diverticulum from the floor of the foregut appears at the $3 \mathrm{~mm}$. stage, and gradually separates off from the rapidly lengthening oesophageal rudiment. Caudal bifurcation with condensation of splanchnopleuric mesoderm gives rise to the primitive lung bud and stem bronchus in the $4 \mathrm{~mm}$. embryo. Further growth and branching of the stem bronchi continues until some 18 generations of subdivision have occurred by the time of birth (Broman, 1923).

During these changes the intra-embryonic coelom becomes modified to form a large pericardial cavity bounded caudally by the septum transversum through which the vitelline and umbilical veins and the ducts of Cuvier pass to the sinus venosus. This pericardial cavity communicates freely on either side of the septum transversum with the peritoneal cavity by way of the pericardio-peritoneal canals. It is into these canals that the developing lung buds project so that each primitive pleural cavity now possesses a wide communication with the pericardial and peritoneal cavities.

Increasing growth of the lung leads to differential enlargement of the pleural cavity which passes behind and lateral to the duct of Cuvier, so producing the pericardio-pleural fold. Closure of the pleuroperitoneal canal results from prollferation of tissue in the free edge of this fold combined with increasing obliquity of the duct of Cuvier due to caudal migration of the heart. It occurs first on the right side, and is usually complete by the $10 \mathrm{~mm}$. stage.

The portion of the primitive vascular plexus in relation to the foregut diverticulum develops further in the mesoderm of the lung buds. Descending branches from the sixth pharyngeal arch arteries reach the plexus to become the pulmonary arteries by the $10 \mathrm{~mm}$. stage.

At this stage the bulbus cordis has become subdivided by growth of the spiral aorticobulbar septum so that blood from the primitive right ventricle reaches the lungs via the dorsal portion of the aortic sac. The oesophageal and bronchial arteries are persistent splanchnic segmental arteries cranial to the coeliac axis, and the small arteries in the pulmonary ligament are probably similarly derived.

\section{CASE Reports}

CASE 1.-B. B., a child, had been subject to attacks of winter bronchitis since birth. He was a little underdeveloped for his age, but no abnormal physical signs were present. Mass radiography showed a rounded tumour projecting beyond the right heart border and lying, in the lateral view, behind the cardiac shadow (Fig. 1). A congen:tal cervical hermivertebra was present.

At operation in October, 1950, a cyst 4 in. in diameter was present in the pulmonary ligament. The overlying pleura was incised and the cyst freed easily from the pericardium and oesophagus. Its upper pole narrowed down to a cylindrical pedicle which extended upwards behind the lung root into the superior mediastinum. Division of the necks of ribs 5 and 6 was necessary to trace the pedicle upwards further, where it disappeared into the root of the neck. It was divided and found to be a hollow tube at the point of division ; the entire intrathoracic portion of the cyst was then removed. The pathological report showed a thick-walled cyst of the parabronchial type lined by ciliated columnar epithelium with aggregations of lymphoid tissue in its walls. 


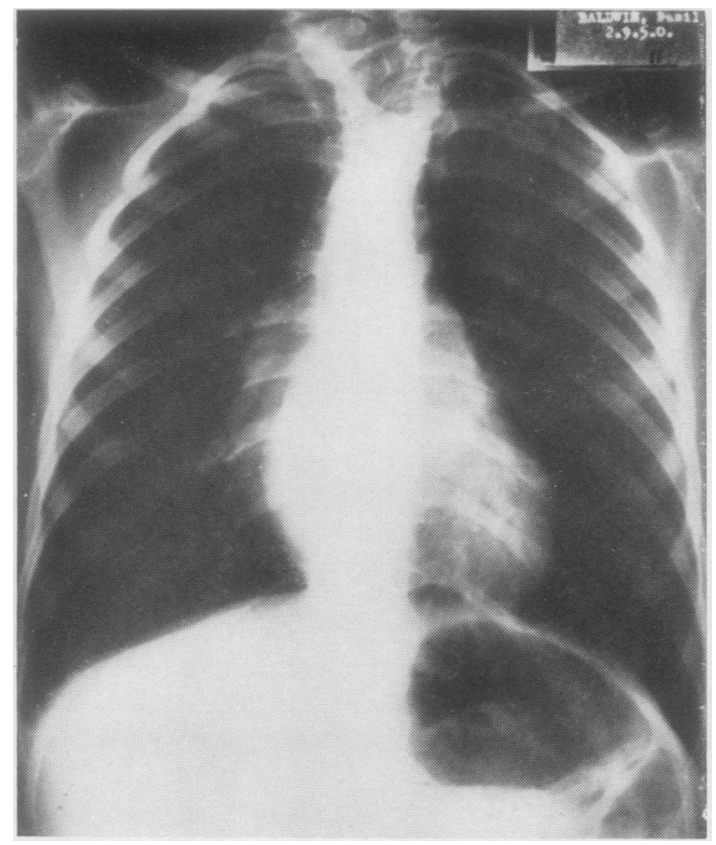

Fig. 1.-Case 1: radiograph showing rounded shadow beyond the right cardiac border, also the cervical hemivertebra.

This patient developed respiratory obstruction due to oedema of the glottis requiring tracheotomy. The subsequent post-operative course was, however, uneventful.

CASE 2.-A. T., a man aged 18 , had no symptoms. Mass radiography showed a rounded tumour projecting from the right side of the mediastinum (Fig. 2). A congenital cervical hemivertebra was present.

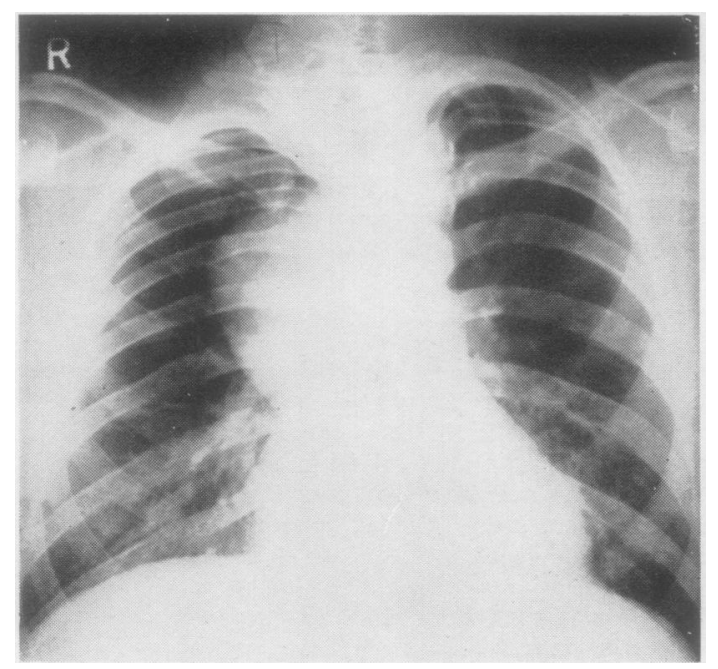

FIG. 2.-Case 2: radiograph showing mediastina! round shadow in the right upper lobe. There is also a cervical hemivertebra.
At operation in January, 1952, a fusiform cystic $\stackrel{\overrightarrow{\vec{S}}}{\stackrel{\vec{S}}{0}}$ mass projecting from the right mediastinum and 0 undergoing waves of vigorous persistalsis was en- $\bar{\sigma}$ countered. It could be freed easily on its mediastinal $\overline{\bar{c}}$ aspect. The azygos vein was divided so that the upward extension of the cyst could be followed. It extended upwards into the root of the neck in close relation to the lateral tracheal wall. The pathological $\vec{\circ}$ report indicated that the cyst was lined by ciliated transitional epithelium. Deep to this were areas of $\vec{\omega}$ mucus-secreting glands, a layer of muscularis mucosa, and two layers of unstriated muscle fibres.

CASE 3.--I. W., a woman aged 21 years, was asymptomatic. Routine radiography showed a rounded shadow in the right upper mediastinum. A diagnostic artificial pneumothorax indicated that the tumour was of extrapulmonary. At operation in June, 1947, the cyst was lying over the right lateral tracheal wall. The azygos vein was divided and on its mediastinal $\vec{C}$ aspect the cyst was adherent to the trachea for a $\mathbb{D}$ length of $1 \frac{1}{2}$ in., directly above the origin of the right main bronchus. This fusion was so complete that dissection of the cyst was carried down to the tracheal mucosa in order to secure its removal. The tracheal cartilaginous rings were splayed out around the $\vec{\theta}$ margins of the cyst attachment. A small tracheal per- जु foration was closed, and the patient made a good post-operative recovery. The cyst was lined with ciliated columnar epithelium and contained cartilage and fibrous tissue within its wall.

CASE 4.-J. B., a man aged 25, was seen at mass radiography to have a right upper mediastinal shadow lying centrally placed in the lateral view.

At operation in May, 1948, a cystic tumour was encountered immediately above the termination of the azygos vein, with the innominate artery in contact with its medial border. The vagus nerve passed downwards over the upper pole of the cyst. The overlying pleura was reflected and the cyst found attached deeply over a large area of tracheal wall. $\stackrel{\searrow}{\times}$ Following removal a deficiency in cartilaginous rings of the trachea was present over an area of 1 sq. in. Histologically this cyst was bronchial in type.

CASE 5.-A. N., a woman aged 18 , had no symptoms. Routine radiography showed a right upper 응 mediastinal shadow. Physical examination and bronchoscopy revealed no abnormality.

At thoracotomy in April, 1947, the cyst lay in the right tracheobronchial angle adherent over a wide $\mathrm{N}$ base to the posterior walls of the trachea and right main bronchus. A small tracheal perforation was closed and the patient made good progress.

CASE 6.-C.A., a woman of 60 years of age, was well until January, 1951, when she coughed up a large quantity of mucoid material. She continued to have $\mathbb{D}$ a cough with mucoid sputum aggravated by lying on $\stackrel{\mathscr{P}}{+}$ the left side. Radiographs showed a large right $\square$ mediastinal cyst containing a fluid level (Fig. 3). $\bar{O}$ Bronchoscopy revealed an abnormal communication $\vec{\Phi}$ into the posterior wall of the right main bronchus just $\frac{\rho}{\mathbb{D}}$ below the level of the right upper lobe orifice. 
At operation in June, 1951, a large cyst, densely adherent to and partly incorporated into the walls of the right main bronchus and carina, was present. During the difficult removal of this cyst the inferior pulmonary vein and right main bronchus were perforated. The patient's post-operative progress was good apart from temporary auricular flutter.

Histologically this cyst had a wall $0.5 \mathrm{~cm}$. thick made up of a respiratory type of epithelium with surrounding areas of smooth muscle, mucous glands, and lymphatic tissue.

CASE 7.-S. I., a boy aged 9, had been subject to winter bronchitis. Radiographs showed a large oval shadow in the left upper zone. Angiocardiography showed normal filling of the great vessels.

At operation in September, 1950, a cystic mass the size of a small orange was encountered. It lay in the upper pole of the left hilum with the main pulmonary artery stretched over its upper convexity and the superior pulmonary vein crossing its lower pole. After freeing these structures the cyst could be seen to be based upon the anterior aspect of the left main bronchus. It was situated so as partially to occlude an oval, left-sided pericardial deficiency, $3 \mathrm{~cm}$. by $2 \mathrm{~cm}$. Histologically the walls of this cyst contained nerve tissue, cartilage, smooth muscle, and mucous glands. No epithelial lining was detected.

CASE 8.-W. A. was a man who had no symptoms. A radiograph revealed a shadow in the left upper zone which on tomography could be seen to be $U$ shaped and appeared to extend medially into the anterior mediastinum.

At operation in May, 1946, the left lung was free and fissured to form a middle lobe. There was an ex:ensive pericardial defect which extended downwards from the aortic arch and had a crescentic lower margin. In its floor was exposed the left auricle and the origin of the left pulmonary artery. The anterior segment of the left upper lobe was occupied by a cystic mass which overlapped the upper margin of the superior pulmonary vein. Left upper lobectomy was carried out. No abnormal vascular arrangements to the left upper lobe were encountered.

Histologically the cyst wall was lined by respiratory epithelium containing cartilage and muscle tissue also. The maximum cartilage was situated in that portion of the cyst nearest to the lobar hilum. The anterior segmental bronchus was small and ended in a blind pouch $\frac{1}{4}$ in. long.

CASE 9.-O. D., a man aged 21, was found to have an abnormal shadow on mass radiography (Fig. 4). A diagnostic artificial pneumothorax showed that the mass had separated from the mediastinum and descended to the level of the lung hilun (Fig. 5). A well-marked pneumopericardium was present.

At operation in March, 1943, a cyst, occupying the lung apex and situated within the substance of an azygos lobe, was encountered. The azygos vein came forward between that part of the lung containing the cyst and the remainder of the right upper lobe to

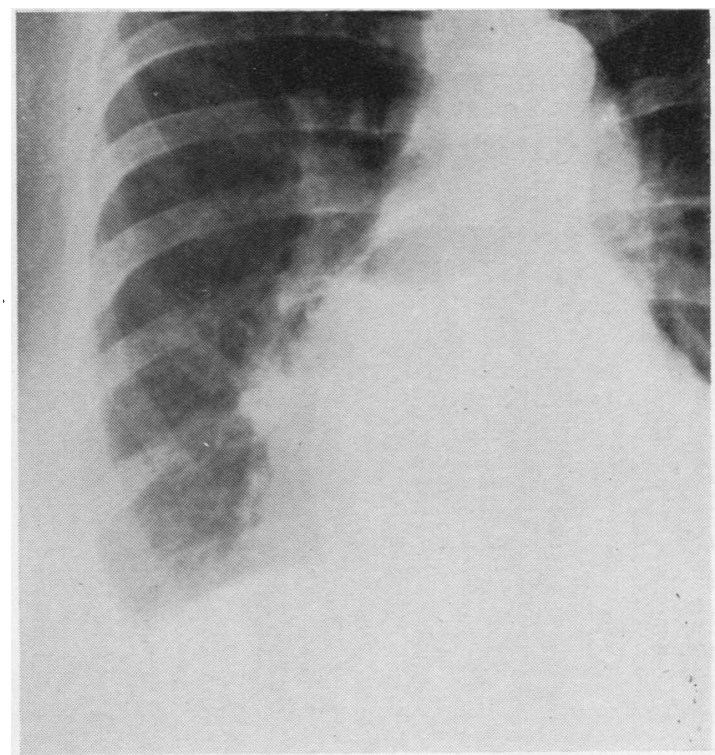

FIG. 3.-Case 6: radiograph showing a rounded shadow with a fluid level.

beyond the superior vena cava, which was larger than usual. Situated immediately above the lung root, between the superior vena cava in front and the trachea behind, was an oval pericardial defect $1 \frac{1}{2}$ in. by 1 in. In the floor of this the ascending portion of the aortic

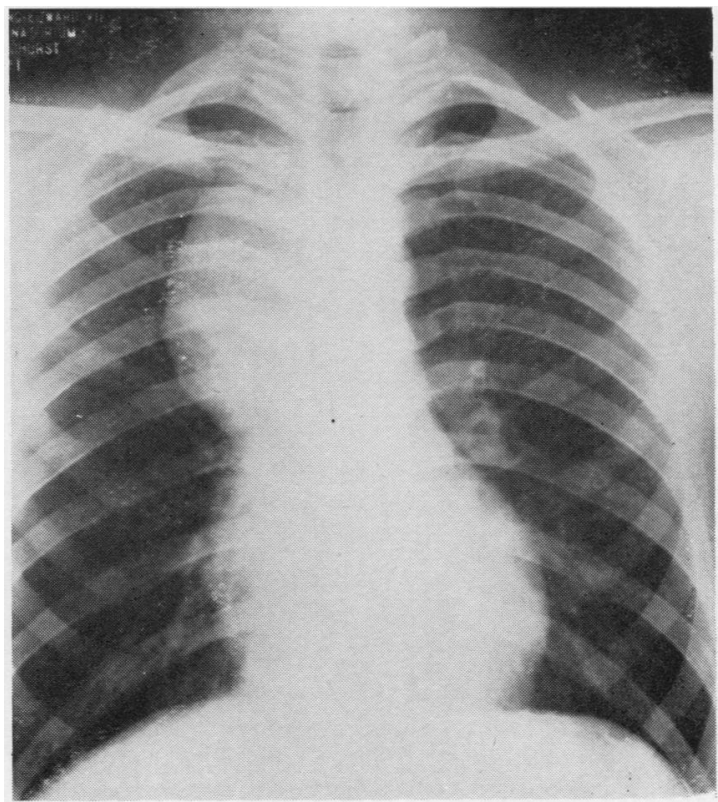

Fig. 4.-Case 9: postero-anterior radiograph showing an abnormal shadow. 


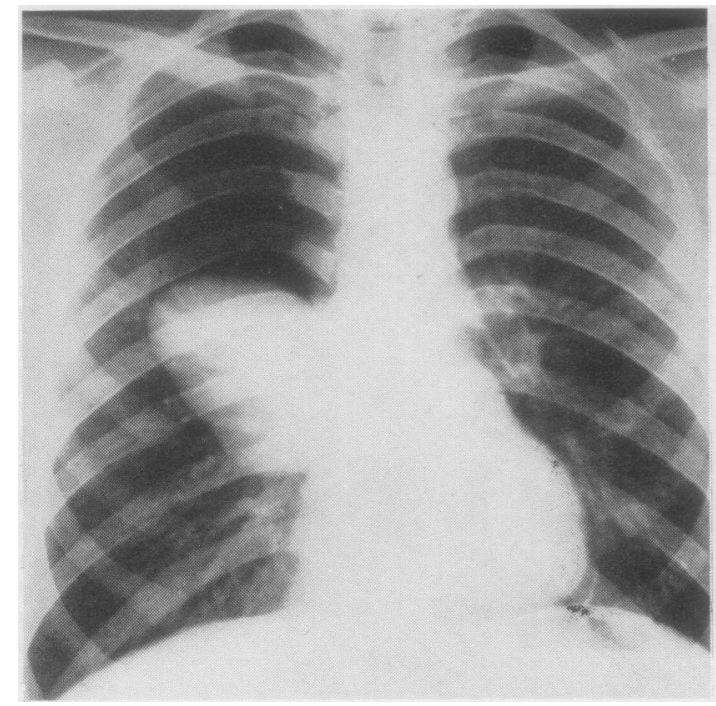

FIG. 5.-Case 9: postero-anterior radiograph after the induction of an artificial pneumothorax showing the descent of the abnormal shadow and a pneumopericardium.

arch was visible. The azygos lobe was removed. A short branch from the upper border of the right pulmonary artery was secured and divided and a small bronchus about $\frac{1}{8}$ in. in diameter.

CASE 10.-S. R., a woman, was asymptomatic. A radiograph showed a shadow projecting from the left mediastinum. Bronchography showed a separate middle lobe bronchus on the left side.

At operation in December, 1946, a cyst lay on the mediastinal aspect of the anterior segment of the left upper lobe. The main pulmonary artery was dissected from its upper pole and the cyst was found firmly attached to the anterior aspect of the left main bronchus. The lower margin was dissected free from the superior pulmonary vein and a separate vein situated as if to supply the middle lobe. The medial border of the cyst was closely adherent to the pericardium with an oval pericardial defect, about 1 sq. in. in size, partly occluded by the adherent cyst. Two small arteries taking origin from the bronchial vessels, one supplying the medial aspect of the cyst and the other its lower pole, were divided in order to remove the cyst.

CASE 11.-This child, A. M., underwent drainage of a lung cyst in 1948 . Repeated episodes of infection continued. He was admitted to hospital in January, 1952. A chest radiograph showed a large cyst situated anteriorly in the right hemithorax with a fluid level.

After preliminary drainage (Fig. 6) and antibiotic therapy thoracotomy was carried out in February, 1952. The chest was opened through the bed of the fifth rib, and the pleural space was partly obliterated by light adhesions. A cyst, approximately $10 \mathrm{~cm}$. by $6 \mathrm{~cm}$., with a smaller one lying posteriorly, was found within the substance of the right upper lobe. On the

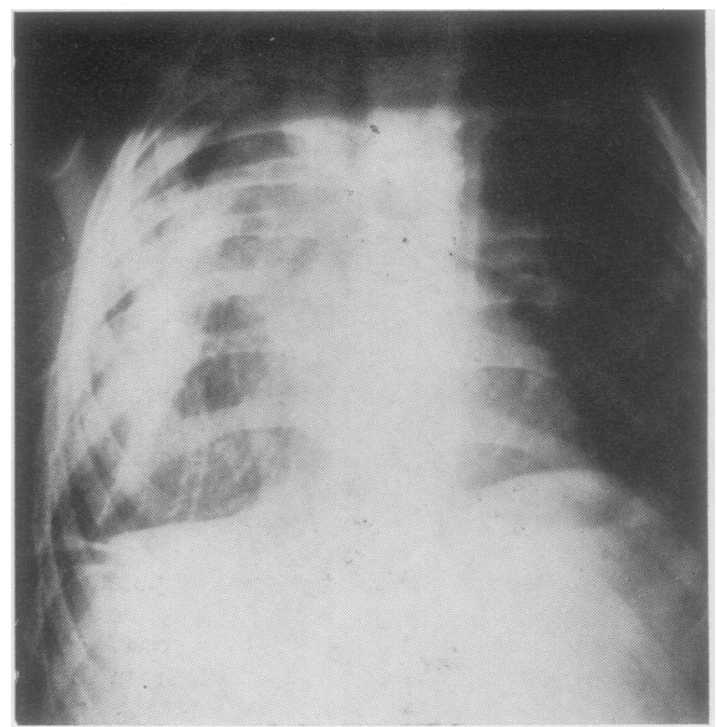

FIG. 6.-Case 11: radiograph after drainage of infected cysts at right apex.

mediastinal aspect an oval pericardial deficiency was observed immediately above the lung root and bounded anteriorly by the superior vena cava. Emerging from the defect a large artery passed to supply the right upper lobe. The main right pulmonary artery was normal in size, although its branch to the right upper lobe was extremely small. The venous drainage of the right upper lobe was quite normal. It was not possible to define the exact point of origin of the large systemic artery to the right upper lobe, whether from the aortic arch itself or the origin of the innominate artery.

CASE 12.-E. C., a woman aged 55 years, had a history of pain in the right lower chest associated with intermittent haemoptyses. Radiographs showed a mass in the right lower lobe, lying posteriorly.

At operation in June, 1946, a hard mass was palpable in the right lower lobe. Resection was carried out and, on division of the pulmonary ligament, an artery the size of the radial artery arising from the thoracic aorta was encountered and divided. The specimen showed a cystic mass situated in the posterior segment of the right lower lobe and supplied by a large systemic artery.

CASE 13.-S. S., a woman aged 30 , had a history of two attacks of left-sided pneumonia with intermittent haemoptyses. A left empyema had been drained.

At operation in March, 1946, a firm mass in the posterior segment of the left lower lobe was present, and two fairly large arteries arising direct from the thoracic aorta and entering the lower lobe were divided. On freeing the diaphragmatic aspect a further large vessel piercing it was encountered. Lower lobectomy was carried out. 

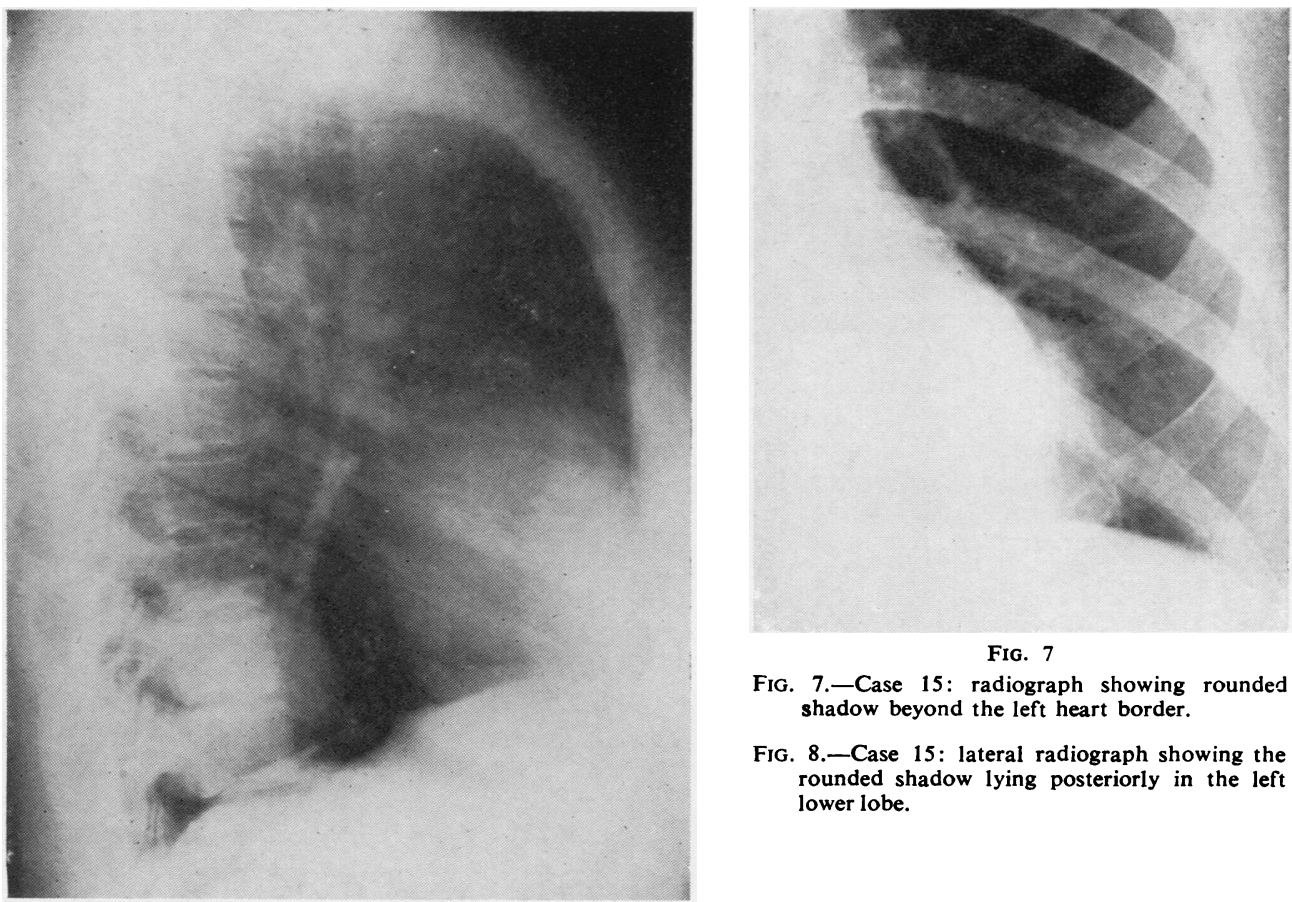

Fig. 7

FIG. 7.-Case 15: radiograph showing rounded shadow beyond the left heart border.

FIG. 8.-Case 15: lateral radiograph showing the rounded shadow lying posteriorly in the left lower lobe.

FIG. 8

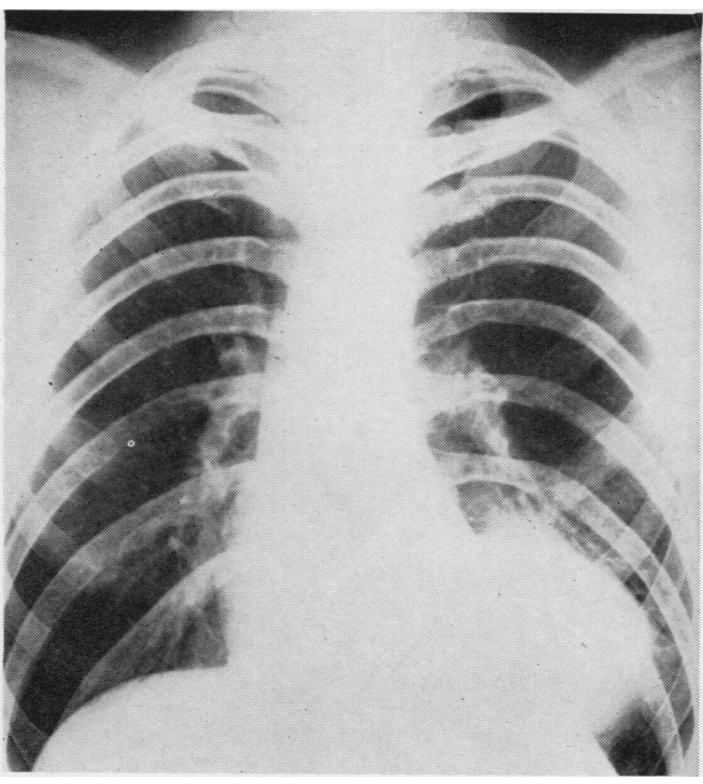

Fig. 9

FIG. 9.-Case 17: radiograph (N.R.B.'s case) in which a rounded mass is shown at the left base.

FIG. 10.-Case 17: lateral radiograph showing the shadow lying posteriorly.

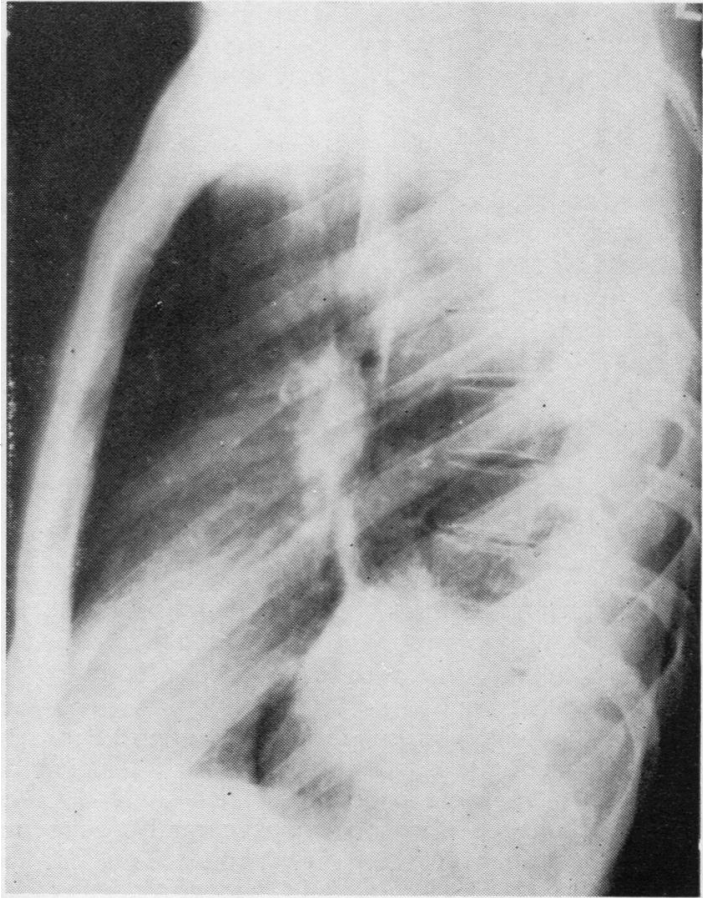

FIg. 10 
CASE 14.-E. G. complained of intermittent left lower chest pain. He had a cough without sputum. Radiographs showed a lesion situated posteriorly in the left lower lobe.

At operation in March, 1951, a firm mass was present in the left lower lobe which was resected. On division of the pulmonary ligament an artery the size of a lead pencil was divided. It arose from the thoracic aorta 2 in. above the diaphragm and entered the lower lobe in the substance of the pulmonary ligament. Pathological examination of the specimen showed a cyst $4 \mathrm{~cm}$. in diameter lined by low columnar ciliated epithelium with occasional goblet cells. The epithelium rested on a well-marked layer of fibrous tissue containing flattened cystic spaces lined by ciliated respiratory epithelium. A large systemic artery, $0.5 \mathrm{~cm}$. in diameter, entered the mass at its posterior inferior margin.

CASE 15.-E. N., aged 32, had had two attacks of left-sided pleurisy. Radiographs showed a round mass in the left lower lobe (Figs. 7 and 8). There was no bronchoscopic abnormality. The Casoni test was normal.

At operation in November, 1952, a cystic mass in the left lower lobe was present with an aberrant artery $0.5 \mathrm{~cm}$. in diameter arising from the thoracic aorta $2 \mathrm{~cm}$. above the diaphragm and entering the lower lobe via the pulmonary ligament. The pathological report showed the lobe to contain a large cyst lined by columnar ciliated epithelium, with smaller surrounding cystic spaces also lined by respiratory epithelium. The aberrant vessel ramified in the walls of this cyst and was of the elastic variety.

CASE 16.-G. M., a man aged 30, complained of haemoptysis and a little purulent sputum daily. Clubbing of the fingers was present, otherwise there were no abnormal physical signs. Radiographs showed a rounded mass in the left lower lobe.

At operation in January, 1953, a firm cystic mass was present in the lower lobe, and an artery the size of the radial artery arose from the aorta $1.5 \mathrm{~cm}$. above the diaphragm and entered the lower lobe. Lobectomy was carried out. This specimen showed a cystic mass lined by respiratory epithelium and containing mucoid material. The vessels were injected with contrast medium.

CASE 17.-G. A., a man aged 39 years, had a history of cough and sputum, occasionally blood-stained, for 12 years. Radiographs showed a mass in the left lower lobe (Figs. 9 and 10).

At operation in February, 1953, a cyst lay posteriorly in the lower lobe. Two aberrant arteries, one arising from the thoracic aorta and the other piercing the diaphragm, were encountered and divided. The specimen showed a rounded cyst containing mucoid material and lined by respiratory epithelium. It was surrounded by cystic spaces. Two aberrant vessels were injected with contrast medium and also the lower lobe branch of the pulmonary artery.

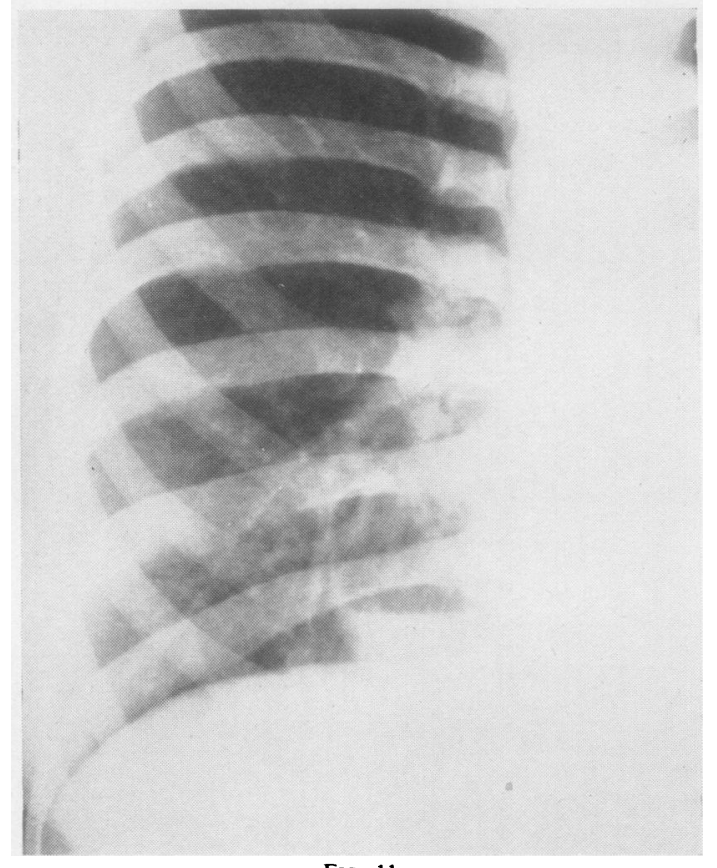

FIG. 11

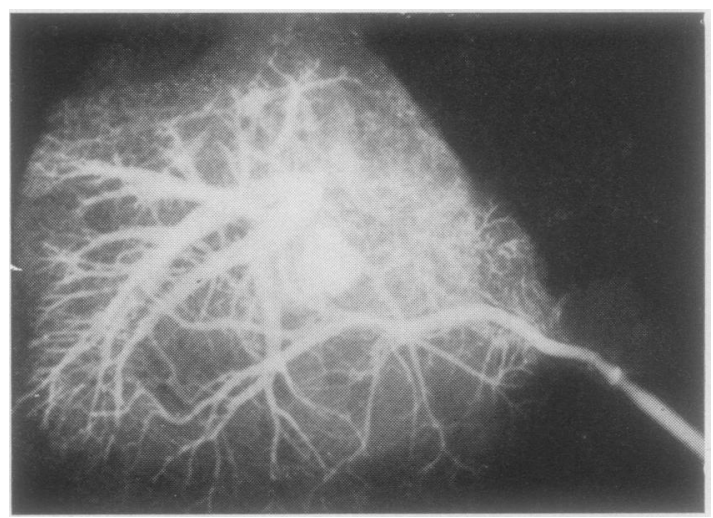

Fig. 12

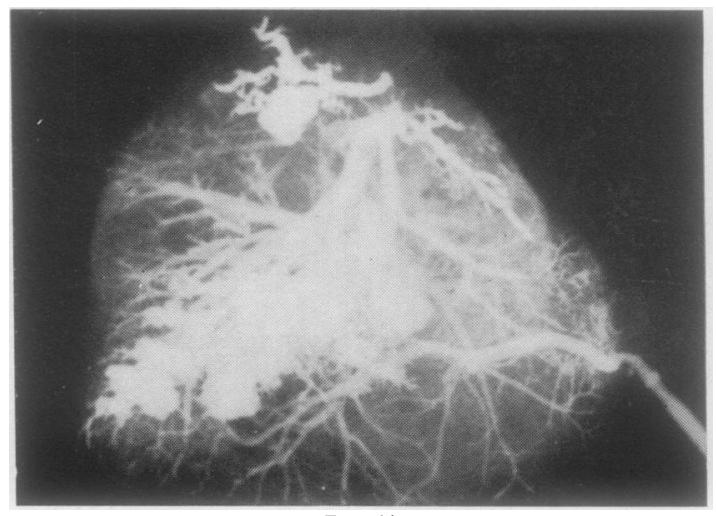

FIG. 13 
FIG. 11.-Case 18: radiograph showing a cystic mass with a fluid level at the right base.

Fig. 12.-Case 18: radiograph after injection of contrast medium into the lower lobe branch of the pulmonary artery and into the aberrant vessel.

FIG. 13.-Case 18: the lobar bronchi have been filled with opaque medium.

CASE 18.-S. W., aged 20 years, had had three attacks of pleurisy and pneumonia on the right side. Radiographs showed a cyst with a fluid level in the right cardiophrenic angle (Fig. 11).

At operation the cyst lay posteriorly in the lower lobe with a single aberrant artery arising from the thoracic aorta to enter the lower lobe in the pulmonary ligament. The pathological report showed that a cyst occupied the posterior basal region of the lower lobe. It was lined by respiratory epithelium. The specimen was radiographed following injection of the aberrant vessels and pulmonary artery with contrast medium (Figs. 12 and 13). No bronchial communication could be demonstrated on injection of the bronchial tree.

CASE 19.-D.S., aged 12, had a history of recurrent episodes of respiratory infection since birth. Radiographs showed an opacity in the right hemithorax with gross tracheal deviation to the right (Fig. 14).

At thoracotomy in July, 1949, dense pleural adhesions were encountered. The right lung was dissected and at the hilum the right main bronchus isolated. It became apparent that no pulmonary artery was present. The right lung was freed further. Two arteries were divided, one arising from the thoracic aorta and supplying the lower lobe, and the other a branch from an intercostal artery also supplying the lung. The venous drainage of this rudimentary right lung was into the inferior vena cava. No pulmonary veins were evident.

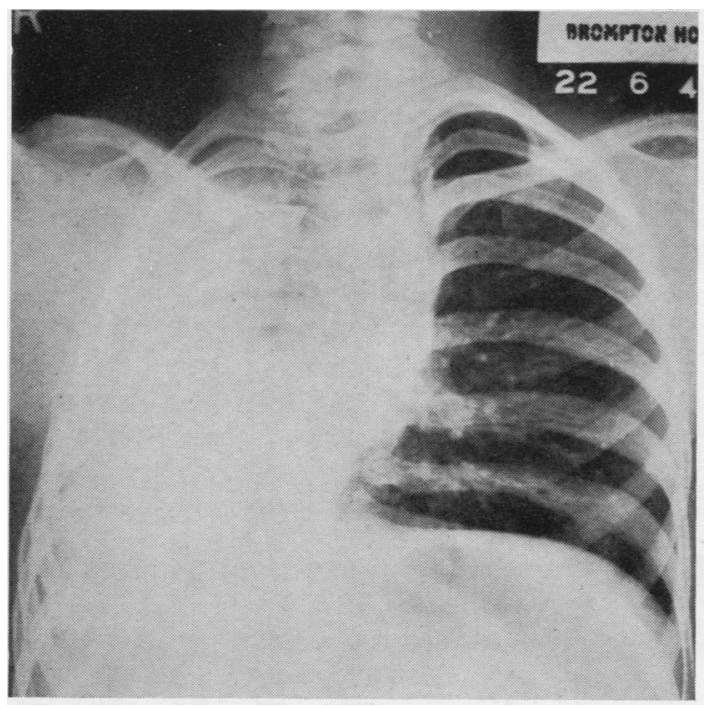

Fig. 14.-Case 19.
Examination of the specimen indicated that it consisted of a small right main bronchus with an irregular dilated bronchus leading to a nubbin of lung tissue which represented the right upper lobe. The lower lobe was grossly bronchiectatic. Injection of the aberrant vessels resulted in a reflex via the single vein draining originally into the inferior vena cava.

The details of these cases are set out in Tables I, II, and III.

\section{TABLE I}

DETAILS OF CASES OF PARATRACHEAL CYST

\begin{tabular}{|c|c|c|c|}
\hline No. & Initials & Age & Developmental Abnormality \\
\hline 1 & B. B. & 9 & $\begin{array}{l}\text { Paratracheai cyst, with origin in neck; cervical } \\
\text { hemivertebra }\end{array}$ \\
\hline 2 & A. $\mathbf{T}$. & 18 & $\begin{array}{l}\text { Cyst lined by respiratory epithelium, with muscu } \\
\text { lar walls; origin in the neck; cervical hemi- } \\
\text { vertebra }\end{array}$ \\
\hline 3 & I. W. & 21 & $\begin{array}{l}\text { Right paratracheal cyst incorporated into } \\
\text { tracheal wall }\end{array}$ \\
\hline 4 & J. B. & 25 & $\begin{array}{l}\text { Right paratracheal cyst; deficiency of cartila- } \\
\text { ginous rings }\end{array}$ \\
\hline 5 & A. N. & 18 & Right paratracheal cyst embedded in tracheal \\
\hline 6 & C. A. & 60 & $\begin{array}{l}\text { Parabronchial cyst incorporated into and in } \\
\text { communication with right main bronchus }\end{array}$ \\
\hline
\end{tabular}

TABLE II BRONCHIAL CYSTS WITH PARTIAL PERICARDIAL

\begin{tabular}{|c|c|c|c|}
\hline No. & Initial & Age & Developmental Abnormality \\
\hline $\begin{array}{l}7 \\
8\end{array}$ & $\begin{array}{l}\text { S. I. } \\
\text { W. A. }\end{array}$ & $\begin{array}{r}9 \\
22\end{array}$ & $\begin{array}{l}\text { Left bronchial cyst; partial pericardial deficiency } \\
\text { Bronchial cyst left upper lobe; left pericardial } \\
\text { defect; left middle lobe bronchus }\end{array}$ \\
\hline 9 & O. D. & 21 & $\begin{array}{l}\text { Azygos lobe and bronchial cyst ; right pericardial } \\
\text { deficiency }\end{array}$ \\
\hline 10 & S. $\mathbf{R}$. & 22 & $\begin{array}{l}\text { Left bronchial cyst; systemic arterial supply; } \\
\text { left pericardial defect }\end{array}$ \\
\hline 11 & A. $\mathbf{M}$ & 9 & $\begin{array}{l}\text { Two bronchial cysts right upper lobe; oval } \\
\text { pericardial deficiency; large systemic artery to } \\
\text { right upper lobe }\end{array}$ \\
\hline
\end{tabular}

TABLE III

DISSOCIATED LUNG CYSTS

\begin{tabular}{|c|c|c|c|c|}
\hline No. & Initials & Age & $\begin{array}{l}\text { Presenting } \\
\text { Feature }\end{array}$ & Developmental Abnormality \\
\hline 12 & E. C. & 55 & Haemoptysis & $\begin{array}{l}\text { R. dissociated lung segment; } \\
\text { single artery from aorta }\end{array}$ \\
\hline 13 & S. S. & 30 & L. empyema & $\begin{array}{l}\text { Dissociated lung segment; two } \\
\text { arteries from aorta }\end{array}$ \\
\hline 14 & E. G. & & $\begin{array}{l}\text { L. pleuritic } \\
\text { pain }\end{array}$ & $\begin{array}{l}\text { Dissociated lung segment; large } \\
\text { vessel from aorta, arising } 2 \text { in. } \\
\text { above diaphragm }\end{array}$ \\
\hline 15 & E. N. & 32 & L. pleurisy & Dissociated lung segment, single \\
\hline 16 & G.M. & 30 & $\begin{array}{l}\text { Cough, } \\
\text { haemoptysis }\end{array}$ & $\begin{array}{l}\text { Dissociated lung segment. L.; } \\
\text { single vessel from aorta }\end{array}$ \\
\hline 17 & G. A & 39 & $\begin{array}{l}\text { L. pleural } \\
\text { pain }\end{array}$ & $\begin{array}{l}\text { Dissociated lung segment; two } \\
\text { aberrant arteries, one through } \\
\text { diaphragm }\end{array}$ \\
\hline 18 & S. W & 20 & $\begin{array}{l}\text { R. } \\
\text { pneumonia }\end{array}$ & $\begin{array}{l}\text { Dissociated lung segment; single } \\
\text { artery from aorta }\end{array}$ \\
\hline 19 & D. S. & 12 & pneumonia & $\begin{array}{l}\text { Partial agenesis } \mathbf{R} \text {. lung; absent } \\
\mathbf{R} \text {. pulmonary artery; large } \\
\text { aberrant arteries from aorta and } \\
\text { intercostals }\end{array}$ \\
\hline
\end{tabular}




\section{Discussion}

Developmental defects of three types are illustrated by this group of patients. Bronchial abnormality is present in all cases. A pericardial deficiency exists in five and a vascular maldevelopment is encountered in 10 cases. In two instances the threefold abnormality is present.

Foetal tissue exclusion or dissociation from the developing tracheobronchial tree is an accepted explanation for the origin of bronchogenic cysts. This actual detachment has been observed in a study of serial sections of an 11-mm. embryo. Two cysts lying in the lung mesenchyme were found in association with hypoplasia of the upper lobe bronchus. This tissue exclusion may vary in site of origin from the cervical region to the periphery of the lower lobes. It is clear that not only does the site of origin vary but also the degree of detachment or exclusion of tissue from the stem bronchus.

It is possible that a similar exclusion from the pulmonary arterial circulation may occur, and that the systemic arteries when present serve to compensate for this partial or complete vascular dissociation from the pulmonary arterial supply.

The first two cases, in which the intrathoracic cystic mass narrowed down to a pedicle lined by respiratory epithelium which disappeared into the cervical region, illustrate a very early developmental exclusion occurring about the $4 \mathrm{~mm}$. embryo stage. It is noteworthy that in both these cases a congenital hemivertebra in the cervical region was radiographically evident.

In the next group of bronchial cysts the exclusion has occurred later in the life history of the growing embryo but is less complete. These cysts are composed of bronchial epithelium, cartilage, and fibrous tissue, and are incorporated in the walls of the trachea and main bronchi. Removal necessitates dissection down to the tracheal or bronchial mucosa, leaving a wide area of deficiency in the cartilaginous rings.

A further group of five cases is set out illustrating bronchial cysts in association with partial pericardial deficiency. This is present on the right side in two cases and on the left in three. Partial pericardial deficiency alone is well recognized; in combination with a bronchial cyst it is less common. Rusby and Sellors (1945) record a case and review the literature and theories of causation. They support the view that the condition is a persistent patency of the pleuropericardial canal. The pulmonary abnormality is related to premature atrophy of the left duct of Cuvier which leads to abnormal development of that portion of the lung which extends cranially and on the medial side of the duct. They conclude that imperfect development of the lung at this point would produce a cyst composed of bronchial elements lying in close relation to the pericardial deficiency. Cases 7 and 8 are of this type, and in the latter a hypoplasia of the anterior segment and its bronchus of the left upper lobe could clearly be demonstrated in the excised specimen. Considerable support to these views is given by consideration of Cases 9, 10, and 11. Right partial pericardial deficiency is present in all these patients in association with cyst formation in the right upper lobe. This finding, as far as we are aware, has not previously been recorded during life. The oval pericardial defect is situated superior to the lung root, limited anteriorly by the superior vena cava and posteriorly by the tracheal wall. In the floor the ascending portion of the aortic arch and in one instance the origin of the innominate artery is clearly visible. Case 9 is remarkable in that the bronchial cyst lay within the substance of an azygous lobe which lay in close proximity to the oval pericardial deficiency. After induction of a right artificial pneumothorax the cyst moved downwards and forwards with the apex of the lung, and a well-marked pneumopericardium was clearly evident on examination of the radiographs. Case 10 is of extreme interest, since there were two small systemic arteries present which were the blood supply to the bronchial cyst. Case 11 illustrated a unique threefold bronchial, pericardial, and vascular abnormality. At operation this young patient was found to have two cysts within the substance of the right upper lobe. An oval pericardial deficiency above the lung root was present through which emerged a large systemic artery to supply the right upper lobe. The right upper lobe branch of the pulmonary artery was very much diminished in size. It is clear that the system:c arterial supply coexisted with a partial exclusion from the pulmonary arterial supply.

A further group of cases is recorded in which the pulmonary maldevelopment is a mass made up of cysts of bronchial origin and surrounded by non-functioning lung tissue. In all these cases a large systemic artery arising from the thoracic or abdominal aorta was present. This condition has received increasing attention since it was first reported by Fisher (quoted by Müller, 1928). Pryce, Holmes Sellors, and Blair in 1947 reported eight cases and related the condition to the lower accessory lung. A consideration of the theories of origin of this condition and the occurrence of 
type I arterial abnormality has led to the theory of vascular competition. This was put forward to explain the aetiology of these cases of intralobar sequestration or dissociated lung segments. The vascular abnormality was considered the prime factor, and the fate of the captured bulbous tips of the developing bronchial tree determines the type of abnormality produced. It is noteworthy that in those cases studied by Pryce (1946) imperfect development of the pulmonary arterial segmental branches was demonstrated in three cases.

These seven cases of dissociated lung cysts with a large systemic adventitious arterial blood supply have been confined to the posterior basal segments, on the left side in five cases and on the right in two. Decrease in size of the lower lobe branches of the pulmonary artery or its segmental branches has been observed at operation and by injection of contrast medium into the vesse's of the excised lobes.

A final case is recorded in which the right pulmonary artery is completely lacking. The right lung is represented by a small right main bronchus supplemented by a cap of rudimentary lung tissue. This hypoplastic lung derives its entire blood supply from an intercostal artery and direct from the lower thoracic aorta. Complete vascular dissociation is present.

Cases 10 to 19 illustrate progressive degrees of hypoplasia of the pulmonary arterial supply to the affected segments or lobes. A systemic blood supply to the pulmonary abnormality is present in all instances. For this reason the systemic arterial abnormality is not regarded as the prime determining factor in the developmental defect. It is considered to be a secondary occurrence compensating for the exclusion of an area of developing lung from its pulmonary arterial supply. It is probable that this change occurs long before closure of the ductus arteriosus and almost certainly before the pulmonary and systemic circulations of the developing embryo have become separated by fusion of the aortic and interventricular septa in the $11 \mathrm{~mm}$. embryo.

\section{SUMMARY}

A group of multiple congenital lung defects is described.

Common to all cases is dissociation of the bronchial or pulmonary tissue from the tracheobronchial tree. This is manifested by the occurrence of bronchogenic and pulmonary cysts at different anatomical sites within the thorax.

The paratracheal cysts of cervical origin are associated with congenital hemivertebrae.

The parabronchial and upper lobe cysts coexist in five instances with partial pericardial deficiency.

In two of these cases, and in eight others where the cystic change is confined to the lower lobes, the bronchopulmonary abnormality receives a systemic arterial blood supply.

There is evidence in the majority of these 10 cases of hypoplasia of the pulmonary artery or its branches, and it is considered to arise when embryonic lung tissue becomes dissociated both from its bronchial and pulmonary vascular supply. The aberrant systemic artery is secondary and compensatory rather than the prime determining factor in the congenital lung defect.

My thanks are due to Sir Clement Price Thomas for the opportunity to discuss freely and record his cases.

In addition I am grateful to Mr. N. R. Barrett and Mr. D. M. E. Thomas for permission to operate upon Cases 15 and 17 respectively.

\section{BIBLIOGRAPHY}

Beck, C. S. (1931). Arch. Surg., Chicago, 22, 282.

Broman, I. (1923). Anat. Anz. Erg., 57, 83.

Gruenfeld, G. E., and Gray, S. H. (1941). Arch. Path., Chicago, 31 392.

Hamilton, W. J., Boyd, J. D., and Mossman, H. W. (1945). Human Embryology. Heffer, Cambridge.

Keith, Sir Arthur (1906). J. Anat., Lond., 41, 6.

(1948). Human Embryology and Morphology, 6th ed. Arnold London.

Müller, H. (1928). In Handbuch der speziellen pathologischen Anatomie und Histologie, ed. F. Henke and $O$. Lubarsch, vol. 3, pt. 1 p. 577. Springer, Berlin.

Pryce, D. M. (1946). J. Path. Bact., 58, 457.

—- Sellors, T. H., and Blair, L. G. (1947). Brit. J. Surg., 35, 18. Rusby, N. L., and Sellors, T. H. (1945). Ibid., 32, 357. 